\title{
Calorimetric and thermogravimetric study on the influence of calcium sulfate on the hydration of ye'elimite
}

\author{
Frank Winnefeld $\cdot$ Stefan Barlag
}

Received: 29 September 2009/Accepted: 21 October 2009/Published online: 3 December 2009

(C) Akadémiai Kiadó, Budapest, Hungary 2009

\begin{abstract}
Calcium sulfoaluminate (CSA) cements, which represent a $\mathrm{CO}_{2}$-friendly alternative to conventional Portland cements, are produced by blending CSA clinker with gypsum and/or anhydrite. The hydration kinetics and the hydrated phase assemblages of the main hydraulic phase ye'elimite (calcium sulfoaluminate) with calcium sulfate were studied by isothermal conduction calorimetry, thermogravimetric analysis, X-ray diffraction analysis and thermodynamic modelling. Two calcium sulfates with different reactivities (gypsum and anhydrite) were applied. It was found that the pure phase without any calcium sulfate addition exhibits very slow hydration kinetics during the first $10 \mathrm{~h}$. The hydration can be accelerated by the addition of calcium sulfate or (less effective) by increasing the $\mathrm{pH}$ of the aqueous phase. The amount of the calcium sulfate determines the ratio between the hydration products ettringite, monosulfate and amorphous aluminium hydroxide. The reactivity of the added calcium sulfate determines the early hydration kinetics. It was found that the more reactive gypsum was better suited to control the hydration behaviour of ye'elimite.
\end{abstract}

Keywords Calcium sulfoaluminate cement - Hydration . Thermodynamic modelling - Ye'elimite

F. Winnefeld $(\bowtie) \cdot$ S. Barlag

Empa, Swiss Federal Laboratories for Materials Testing and

Research, Überlandstrasse 129, 8600 Dübendorf, Switzerland

e-mail: frank.winnefeld@empa.ch

URL: www.empa.ch/abt135

\section{Introduction}

The manufacturing of Portland cement, which is nowadays mainly used as binder in concrete structures, counts for about $5 \%$ of the total man-made $\mathrm{CO}_{2}$-emissions. Thus, there is an increasing driving force for research and development in the field of more environmental friendly binders like blended Portland cements and non-Portland cements. Among others, the production of calcium sulfoaluminate cements (CSA), based on the CSA phase (ye'elimite, $4 \mathrm{CaO} \cdot 3 \mathrm{Al}_{2} \mathrm{O}_{3} \cdot \mathrm{SO}_{3}$, also written as $\mathrm{C}_{4} \mathrm{~A}_{3} \overline{\mathrm{S}}$ in cement notation $)^{1}$ is a promising low- $\mathrm{CO}_{2}$ alternative $[1,2]$. In contrary to Portland cements, where the main properties like strength are due to the presence of calcium silicate hydrates, CSA cements are systems based on calcium aluminate sulfate hydrates.

The CSA clinker can be made from calcium sulfate, limestone and bauxite at a temperature of about $1,250{ }^{\circ} \mathrm{C}$, which is $200{ }^{\circ} \mathrm{C}$ lower than for Portland cement clinker. Compared to the typical Portland cement phase alite (tricalcium silicate) $\left(1.80 \mathrm{~g} \mathrm{CO}_{2}\right.$ per $\mathrm{mL}$ of the cementing phase), CSA releases only $0.56 \mathrm{~g} \mathrm{CO}_{2}$ per $\mathrm{mL}$ cementing phase during its production. In addition, this type of clinker can be ground easier compared to ordinary Portland cement. Besides ye'elimite, CSA clinkers usually contain other phases like dicalcium silicate (belite), tetracalcium aluminate ferrate, anhydrite, gehlenite or mayenite.

Typically about 15-25 mass\% of gypsum and/or anhydrite are interground with the clinker for optimum setting time, strength development and volume stability [2-7]. The hydration of the obtained CSA cements and their properties mainly depend on the amount and reactivity of the added calcium sulfate [8-16].

${ }^{1}$ Cement notation: $\mathrm{A}=\mathrm{Al}_{2} \mathrm{O}_{3}, \mathrm{C}=\mathrm{CaO}, \mathrm{H}=\mathrm{H}_{2} \mathrm{O}, \overline{\mathrm{S}}=\mathrm{SO}_{3}$. 
As main crystalline hydration products, ettringite and monosulfate are formed together with amorphous aluminium hydroxide (Eqs. 1, 2). The ratio between ye'elimite and calcium sulfate determines the ratio between ettringite and monosulfate in the final product. Above a molar ratio of calcium sulfate to ye'elimite of 2 , only the reaction (2) will occur.

$$
\begin{aligned}
\mathrm{C}_{4} \mathrm{~A}_{3} \overline{\mathrm{S}}+18 \mathrm{H} \rightarrow & \mathrm{C}_{3} \mathrm{~A} \cdot \mathrm{C} \overline{\mathrm{S}} \cdot 12 \mathrm{H} \\
& +2 \mathrm{AH}_{3} \text { (monosulfate formation) } \\
\mathrm{C}_{4} \mathrm{~A}_{3} \overline{\mathrm{S}}+2 \mathrm{C} \overline{\mathrm{S}} \mathrm{H}_{2}+34 \mathrm{H} \rightarrow & \mathrm{C}_{3} \mathrm{~A} \cdot 3 \mathrm{C} \overline{\mathrm{S}} \cdot 32 \mathrm{H} \\
& +2 \mathrm{AH}_{3} \text { (ettringite formation) }
\end{aligned}
$$

In technical products containing accessory phases additional hydration products might be present like calcium silicate hydrates, strätlingite, monocarbonate or calcium aluminate hydrates [15-19].

While the application of CSA cements in Europe is not yet widespread, they have been produced, used and standardised in China since about 30 years [3-5]. Depending on the level of calcium sulfate addition, CSA cements with different properties can be obtained. Therefore, a formula for the calculation of optimum sulfate level to obtain the different types of CSA cements was developed in China, which is based on stoichiometric calculations $[4,6]$ :

$C_{\mathrm{T}}=0.13 M \frac{A}{\overline{\mathrm{S}}}$

where $C_{\mathrm{T}}$, ratio gypsum/clinker by mass; $A$, mass $\%$ of ye'elimite in the clinker; $\overline{\mathrm{S}}$, mass $\%$ of $\mathrm{SO}_{3}$ in the gypsum; $M$, molar ratio gypsum/ye'elimite; and 0.13 , a stoichiometric factor containing all the conversions between mass\% and mole.

The value $M$ (and also whether gypsum or anhydrite is used) is related to the type of CSA cement. $M=0-1.5$ with a low calcium sulfate content yields a rapid hardening or high-strength cement, which is also confirmed by the experimental data given in [15]. Higher sulfate levels are applied to formulate expansive $(M=1.5-2.5)$ and selfstressing cements $(M=2.5-6)$.

Shrinkage compensated, expansive and self-stressing cements generate expansive (compressive) stresses in the final, dried paste, mortar or concrete, which are low $(<1 \mathrm{MPa})$ in the case of shrinkage compensated and high (up to $8 \mathrm{MPa}$ ) in the case of self-stressed systems [20]. The latter have to be restrained by a suitable reinforcement in order to avoid excessive expansion and crack formation.

Thus, according to Eq. 3, the properties of the CSA cements are directly related to the formation kinetics and to the total amount of the voluminous ettringite phase in the hardened system.
However, in the absence of calcium oxide or calcium hydroxide, which both accelerate ettringite formation [15], CSA cements are often dimensionally stable [17]. They even exhibit a chemical shrinkage, which means that the volume of the anhydrous material plus the mixing water is higher than the volume of the hydrated paste. This is related to the fact that the apparent density of the water bound in the hydrate phases like ettringite is higher than the density of free water. It can be calculated by thermodynamic modelling that CSA cements should have a theoretical chemical shrinkage of about $11 \mathrm{~cm}^{3} / \mathrm{g}$ cement after 28 days [16], whereas an ordinary Portland cement reaches about $4-5 \mathrm{~cm}^{3} / \mathrm{g}$. Chemical shrinkage of a CSA cement was experimentally determined in [21] and found to be in the same order of magnitude as the predicted value. However, expansion may occur if ettringite forms in reasonable amounts after setting. Several mechanisms are discussed in literature [20]: (i) the topochemical formation of ettringite at certain locations leading to local stresses, (ii) crystallisation pressure generated by an oriented, anisotropic growth of ettringite, (iii) water adsorption at the surface of colloidal ettringite causing interparticle repulsion and (iv) osmotic pressure at a semi-permeable membrane around the anhydrous cement particles.

The optimum calcium sulfate content is one of the key issues concerning the relevant properties like rapid hardening, high strength and expansive with respect to the application of CSA cements. Thus, the hydration of pure synthetic ye'elimite was examined in this study using several blends with gypsum and anhydrite by means of conduction calorimetry, thermogravimetric analysis (TGA) and X-ray diffraction (XRD).

As the $\mathrm{pH}$ value of the liquid phase (pore solution) should greatly influence the reaction kinetics [17], the experiments were carried out in water and in diluted potassium hydroxide solutions. The experimental results will be compared with thermodynamic calculations of the stable hydrate assemblages.

\section{Materials and methods}

Calcium sulfoaluminate (ye'elimite) was synthesized from a stoichiometric mixture of calcite, aluminium oxide and gypsum. The analytical grade materials (Fluka) were homogenised and then pelletized with water. Afterwards the pellets were fired in a laboratory kiln at $1,300{ }^{\circ} \mathrm{C}$ for $4 \mathrm{~h}$. The obtained material was identified by XRD as pure ye'elimite. It exhibited a free calcium oxide content of 0.2 mass $\%$ as determined using the extraction method according to [22]. Prior to the use in the experiments the powder was ground using an automatic agate mortar grinder mill (Retsch RM100). The final product exhibited a 
bulk density of $2.60 \mathrm{~g} / \mathrm{cm}^{3}$ and a specific surface of $5,520 \mathrm{~cm}^{2} / \mathrm{g}$ according to EN 196-6 (Blaine method).

Analytical grade calcium sulfate dihydrate and potassium hydroxide (Fluka) were used. The latter was dissolved in demineralised water to obtain 0.1 and 0.01 molar solutions. Anhydrite was prepared by burning calcium sulfate dihydrate in a laboratory furnace at $700{ }^{\circ} \mathrm{C}$ for $2 \mathrm{~h}$. Anhydrite formed under these conditions exhibits much slower dissolution kinetics than calcium sulfate dihydrate $[8,11,15]$.

In the experiments, ye'elimite was blended with different quantities of gypsum or anhydrite (molar ratios 1:1, 1:2, $1: 3$ and $1: 4$ ) to cover the whole range between undersupply and surplus of calcium sulfate with respect to Eq. 2. The hydration experiments were carried out either in demineralised water or in aqueous potassium hydroxide solution (0.01 molar and 0.1 molar) in order to study the impact of $\mathrm{pH}$ on the hydration kinetics of ye'elimite. All experiments were done at $20{ }^{\circ} \mathrm{C}$.

A conduction calorimeter (Thermometric TAM Air) was used to determine the hydration heat flow using the admix ampoules described in [23]. $1 \mathrm{~g}$ of solid was weighed into the ampoule, and $2 \mathrm{~g}$ of liquid were filled into the two syringes. The admix ampoule was then inserted into the calorimeter. After equilibration the liquid was injected into the ampoule, and the hydration heat flow was recorded for $18 \mathrm{~h}$.

Similar pastes were prepared by blending solid and liquid in a plastic container using a spatula for $2 \mathrm{~min}$. After $18 \mathrm{~h}$, the hydration was stopped by submersing the crushed paste in isopropanol, filtering and washing the residue first with isopropanol and then with diethyl ether. Afterwards, the samples were ground by hand to a grain size $<0.063 \mathrm{~mm}$. TGA was carried out in $\mathrm{N}_{2}$ atmosphere on about $10 \mathrm{mg}$ of sample using a Mettler-Toledo TGA/SDTA 851 instrument at $20^{\circ} \mathrm{C} / \mathrm{min}$ up to $980{ }^{\circ} \mathrm{C}$. XRD patterns were measured with a Panalytical X'Pert Pro powder diffractometer equipped with an $\mathrm{X}^{\prime}$ Celerator detector in a $2 \theta$ range of $5-80^{\circ}$.

Thermodynamic calculations were carried out using the geochemical GEMS-PSI software [24], coupled with the cement-specific CEMDATA database [25]. Recent examples of the application of thermodynamic modelling to cement hydration using the GEMS-PSI code are given in $[16,26,27]$.

\section{Results and discussion}

\section{Conduction calorimetry}

The influence of the gypsum to ye'elimite molar ratio on the hydration heat flow of pastes mixed with deionised water is shown in Fig. 1. Without gypsum, the pure ye'elimite phase shows two maxima in the heat flow curve. The first occurs directly when the water is added and can be attributed to heat of wetting and very early hydration reactions (Fig. 1a). After that, a so-called dormant period occurs with a low heat flow during about $10 \mathrm{~h}$. This long dormant period could be explained by a surface coverage of the clinker grains by early hydration products. Afterwards the heat flow increases again, reaching a second maximum after about $15 \mathrm{~h}$ of hydration (Fig. 1b). This heat event covers the main part of the hydration reactions and is responsible for setting and hardening of the paste. Beyond the maximum, the heat flow decreases without showing any other maximum or shoulder in the heat flow curve. Technical clinkers show a similar behaviour when hydrated at a water/cement ratio of 0.7 with a very long dormant period compared to Portland cements [15]. In [28] a faster kinetics with a dormant period of about $2 \mathrm{~h}$ is reported for pure ye'elimite hydrated at $25{ }^{\circ} \mathrm{C}$, but the synthesis procedure and experimental conditions are different.
Fig. 1 Conduction calorimetry of ye'elimite pastes: influence of gypsum addition, a zoom on the first $30 \mathrm{~min}, \mathbf{b}$ measurement $0-18 \mathrm{~h}$
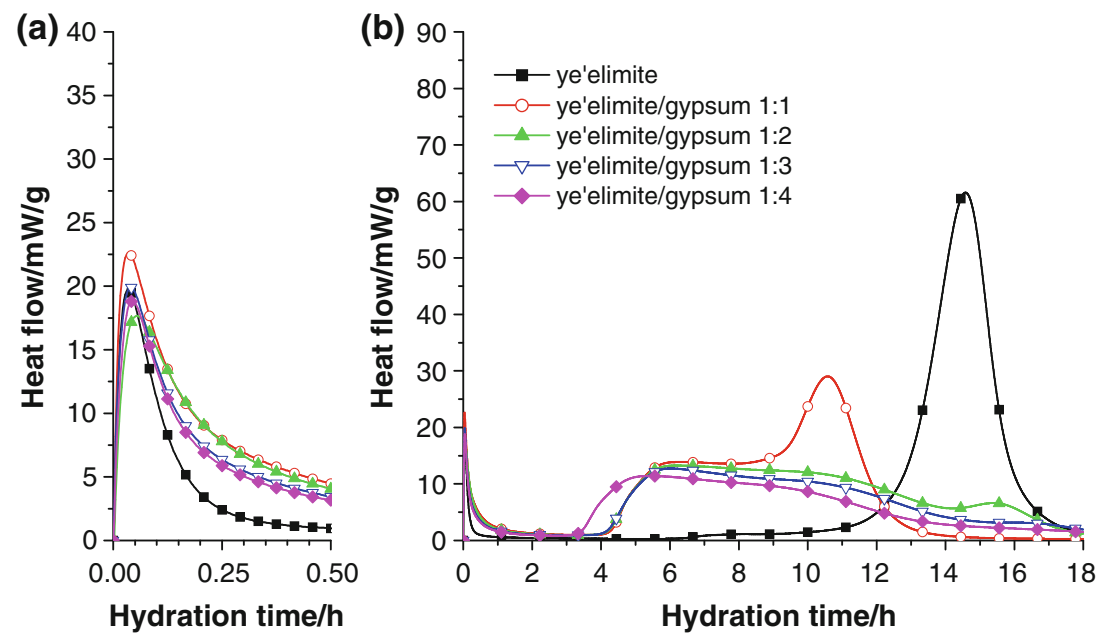
All mixtures with gypsum show a similar initial peak as the pure ye'elimite paste (Fig. 1a). However, this heat event appears to be more intense in the mixtures with gypsum, indicating a higher intensity of the reactions and/ or the formation of different products during very early hydration. When gypsum is added, the dormant period is shortened to about 2-3 h (Fig. 1b). Thus, gypsum accelerates the hydration of the ye'elimite phase, which is comparable to the behaviour of calcium aluminate cements [29].

The heat flow of the subsequent peaks (one or two) exhibits lower values than for the pure ye'elimite paste. The two samples with the lowest gypsum additions exhibit two heat flow maxima after the dormant period. The first is in both cases after about $6 \mathrm{~h}$, the second after $10.5 \mathrm{~h}$ (molar ratio $1: 1$ ) or $15.5 \mathrm{~h}$ (molar ratio $1: 2$ ). On the contrary, the samples with higher gypsum contents display only one maximum beyond the dormant period. It can be assumed that the second maximum after the dormant period indicates the depletion of the gypsum, which results in the formation of monosulfate (according to Eq. 2) instead of ettringite (Eq. 1). This maximum does not occur in the samples with molar ratios $1: 3$ and 1:4, as they exhibit a surplus of gypsum with respect to the formation of ettringite.

Figure 2 shows the influence of the anhydrite to ye'elimite molar ratio on the hydration heat development. The initial peak directly after water addition (Fig. 2a) is not significantly influenced by the addition of anhydrite, probably because anhydrite has less impact on the very early reactions due to its slow dissolution kinetics. It is found as with the gypsum, that the calcium sulfate addition generally accelerates the hydration of the ye'elimite (Fig. 2b), shortening the dormant period to $4 \mathrm{~h}$ (molar ratio $1: 1$ ) or $2 \mathrm{~h}$ (all other ratios). The shapes of the curves obtained from the mixtures with anhydrite are different from those of the mixtures with gypsum. The dissolution kinetics of anhydrite being much slower than that of gypsum could result in an undersupply of calcium and sulfate ions with respect to the formation of ettringite, which could slow down the formation of ettringite and favour the reaction to monosulfate. This is in agreement with $[11,13$, 15], where a lower amount of ettringite is formed during early hydration when anhydrite is used instead of gypsum. It may result in a poor early strength development. This behaviour of anhydrite is confirmed by a study on the pore solution chemistry of two technical CSA cements [16]. It was shown that the pore solution of the cement containing gypsum was saturated in calcium and sulfate with respect to gypsum, while with the cement with anhydrite addition the pore solution was undersaturated in calcium and sulfate with respect to gypsum or anhydrite. This indicates that the dissolution of anhydrite is kinetically hindered. Also a study using Raman spectroscopy to monitor the hydration of ye'elimite based pastes containing gypsum and anhydrite [30] found that the anhydrite started to react only when most of the gypsum had been consumed.

The influence of potassium hydroxide solutions on the hydration kinetics of ye'elimite is shown in Fig. 3. On one hand, the initial peak directly after mixing is significantly increased when a $\mathrm{KOH}$ solution is applied instead of deionised water (Fig. 3a). This might be due to an enhanced dissolution and precipitation of more hydrate phases during the first minutes of hydration. On the other hand, the hydration of ye'elimite is accelerated by the alkaline solutions, as the main hydration peak occurs earlier and is sharper (Fig. 3b). In both cases the higher concentrated $\mathrm{KOH}$ solution exhibits the stronger effect.

Mixtures of ye'elimite and calcium sulfate, as shown in Fig. 4 for the mixture of ye'elimite with gypsum with a molar ratio of 1:1, are also accelerated if $\mathrm{KOH}$ solutions are used instead of deionised water (Fig. 4b). The initial peak (Fig. 4a) is also significantly increased when a 0.1 molar $\mathrm{KOH}$ solution is used.
Fig. 2 Conduction calorimetry of ye'elimite pastes: influence of anhydrite addition, a zoom on the first $30 \mathrm{~min}, \mathbf{b}$ measurement $0-18 \mathrm{~h}$
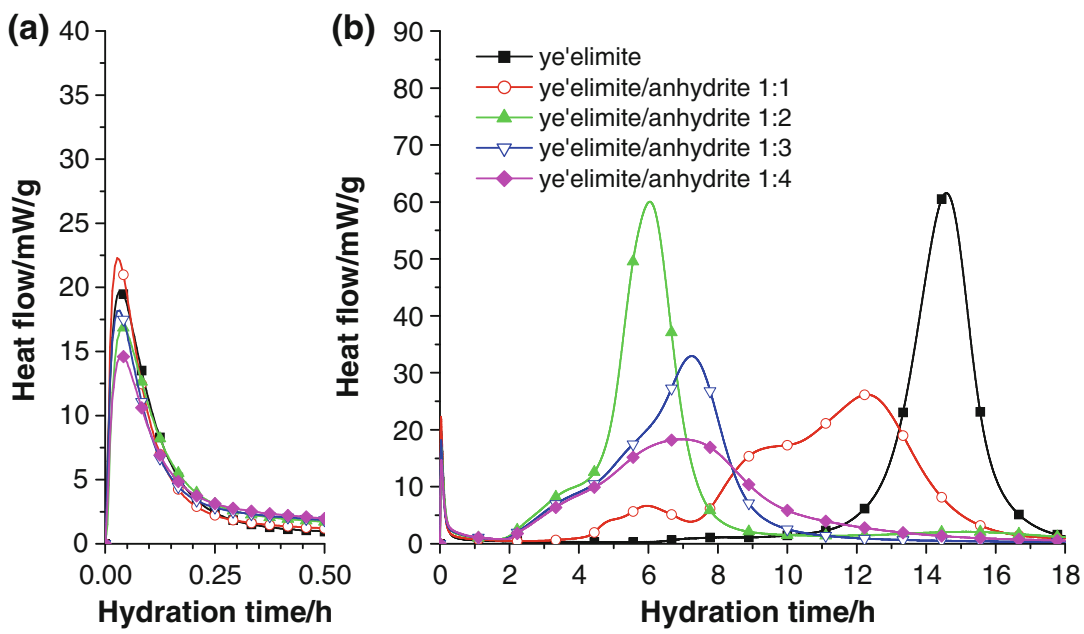
Fig. 3 Conduction calorimetry of ye'elimite pastes: influence of $\mathrm{KOH}$ solution, a zoom on the first $30 \mathrm{~min}$, b measurement 0 $18 \mathrm{~h}$

Fig. 4 Conduction calorimetry of ye'elimite paste blended with gypsum: influence of $\mathrm{KOH}$ solution, a zoom on the first $30 \mathrm{~min}, \mathbf{b}$ measurement $0-18 \mathrm{~h}$
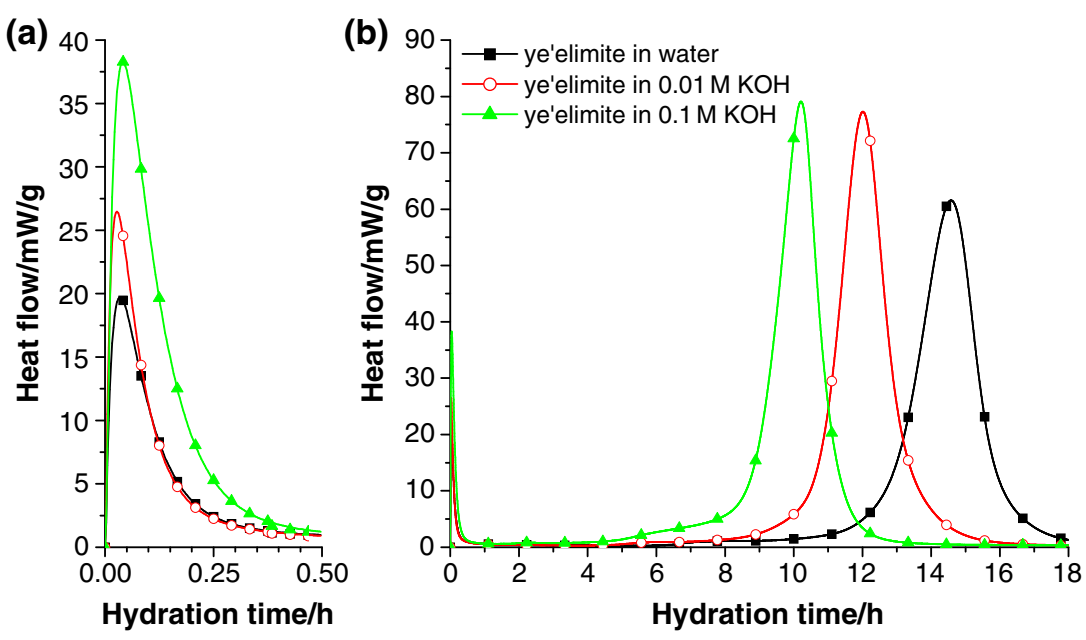

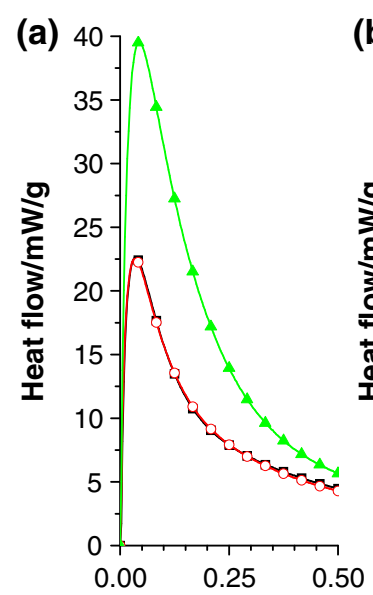

Hydration time/h

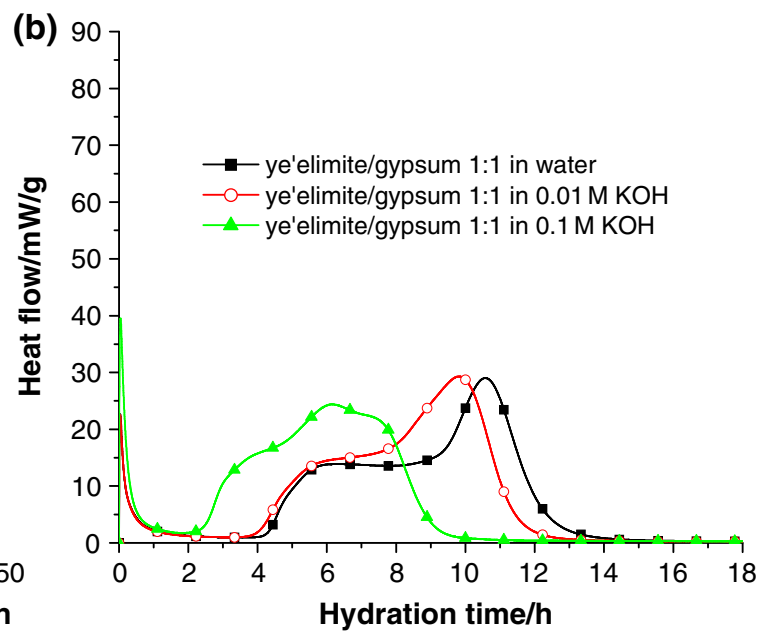

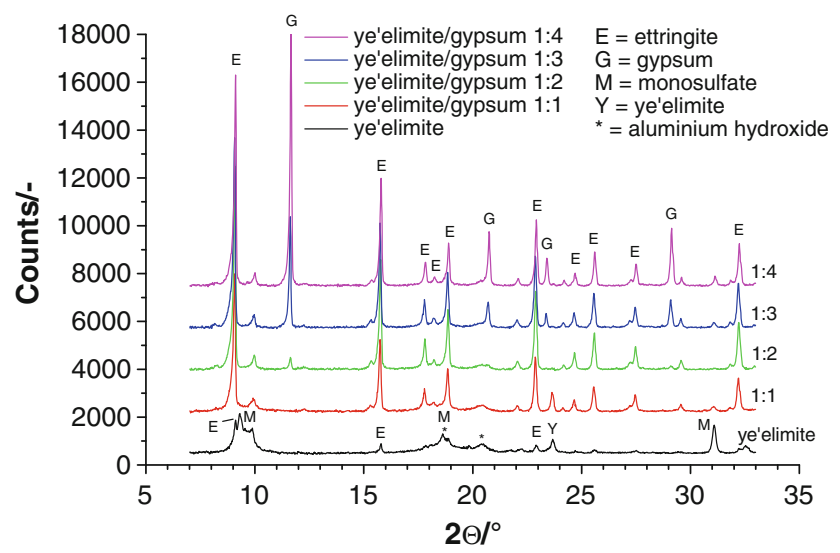

Fig. 5 X-ray diffraction analyses of ye'elimite pastes after $18 \mathrm{~h}$ of hydration: influence of gypsum addition

$\mathrm{X}$-ray diffraction and thermogravimetry

XRD and TGA analyses of the ye'elimite/gypsum blends after $18 \mathrm{~h}$ of hydration are shown in Figs. 5, 6. The XRD pattern (Fig. 5) of the pure ye'elimite paste reveals that

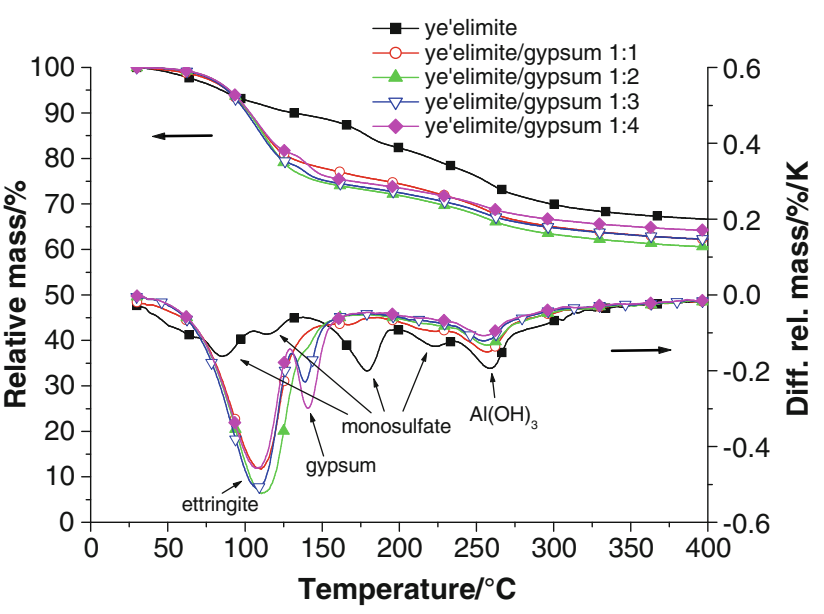

Fig. 6 Thermogravimetric analyses of ye'elimite pastes after $18 \mathrm{~h}$ of hydration: influence of gypsum addition

traces of $\mathrm{C}_{4} \mathrm{~A}_{3} \overline{\mathrm{S}}$ are still present after $18 \mathrm{~h}$. Monosulfate was identified as the main hydration product, besides some ettringite. Some authors $[9,10]$ did not report the 
occurrence of ettringite, while it was postulated by [23] that hydration products in pure ye'elimite pastes could also be produced via the reaction given in Eq. 4. However, $\mathrm{C}_{3} \mathrm{AH}_{6}$ was not identified in the present study. It was perhaps below detection limit of the XRD measurements.

$$
\begin{aligned}
\mathrm{C}_{4} \mathrm{~A}_{3} \overline{\mathrm{S}}+80 \mathrm{H} \rightarrow & \mathrm{C}_{3} \mathrm{~A} \cdot 3 \mathrm{C} \overline{\mathrm{S}} \cdot 32 \mathrm{H}+\mathrm{C}_{3} \mathrm{~A} \cdot \mathrm{C} \overline{\mathrm{S}} \cdot 12 \mathrm{H} \\
& +2 \mathrm{C}_{3} \mathrm{AH}_{6}+8 \mathrm{AH}_{3}
\end{aligned}
$$

Aluminium hydroxide occurs in an X-ray amorphous form, which only shows some broad background in the XRD pattern, where crystalline $\mathrm{Al}(\mathrm{OH})_{3}$ (gibbsite) would exhibit its main reflections. Similar information can be obtained from the TGA analysis (Fig. 6), where monosulfate can clearly be identified. In contrary to the XRD, TGA is suitable to identify amorphous $\mathrm{Al}(\mathrm{OH})_{3}$, which loses its bound water around $250-280{ }^{\circ} \mathrm{C}$. Ettringite cannot clearly be identified in TGA, as it is present in only minor amounts and its dehydration peak overlaps the one of monosulfate.

When gypsum is added to the ye'elimite in a molar ratio of $1: 1$, ettringite occurs as the main hydration product of the paste, whereas monosulfate is hardly visible in the XRD pattern, probably due to poor crystallinity. In the TGA diagram some water loss can be observed in the derivative curve around $170{ }^{\circ} \mathrm{C}$, which can be attributed to monosulfate. In addition, it appears that slightly less $\mathrm{Al}(\mathrm{OH})_{3}$ is produced when gypsum is added compared to the pure ye'elimite which is due to the dilution of the ye'elimite with gypsum, leading to less aluminium in the mixture.

In the 1:2 mixture no traces of monosulfate are observed, neither with XRD nor with TGA. Ettringite and amorphous $\mathrm{Al}(\mathrm{OH})_{3}$ are the only hydration products. The hydration reaction was not complete, as traces of unreacted gypsum can be identified in the XRD pattern.

Beyond the ye'elimite to gypsum molar ratio 1:2, gypsum is always present in the XRD pattern and can also be identified easily in the TGA diagram. Those mixtures contain a surplus of calcium sulfate with respect to the formation of ettringite, according to Eq. 1.

The mixtures of ye'elimite with anhydrite exhibit the same hydrate assemblages than those with gypsum (Figs. 7, 8). The slower dissolution kinetics of anhydrite compared to gypsum is evident from the XRD patterns. Unreacted anhydrite can be identified in all ye'elimite/anhydrite mixtures, even in those with molar ratios 1:1 and 1:2, where the anhydrite amount could theoretically been used up in the production of ettringite. Moreover, secondary gypsum is not observed in those samples. Thus, any calcium and sulfate originating from the dissolution of anhydrite is rapidly consumed by the formation of ettringite.

When $\mathrm{KOH}$ solutions are used as liquid reagent, the same hydrate assemblages are present after $18 \mathrm{~h}$ as in the

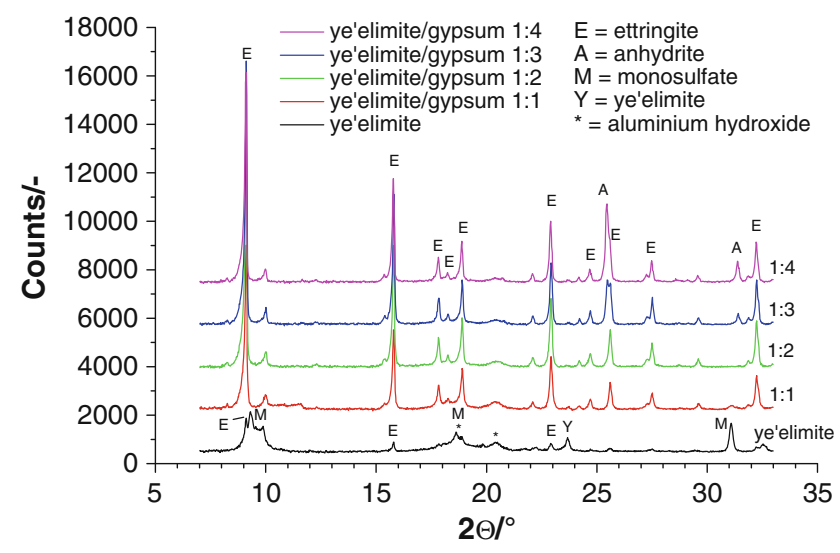

Fig. 7 X-ray diffraction analyses of ye'elimite pastes after $18 \mathrm{~h}$ of hydration: influence of anhydrite addition

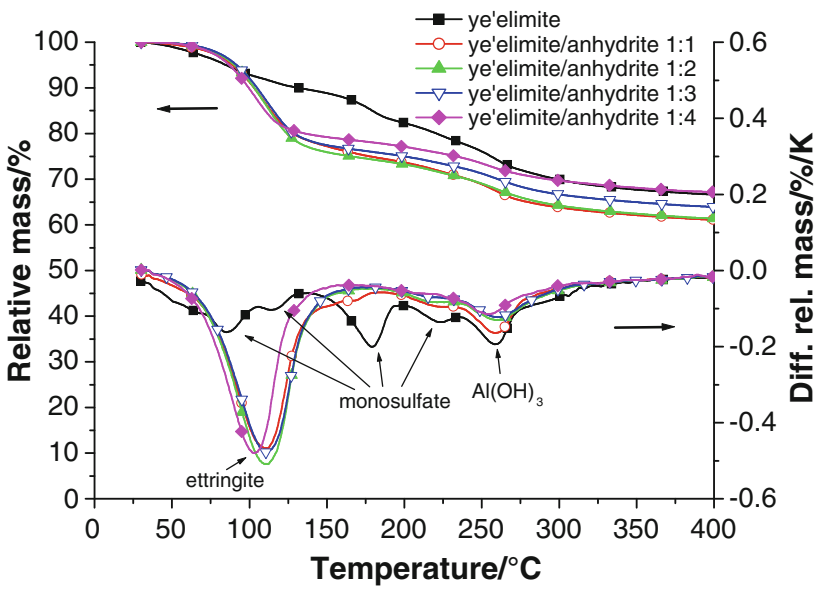

Fig. 8 Thermogravimetric analyses of ye'elimite pastes after $18 \mathrm{~h}$ of hydration: influence of anhydrite addition

pastes prepared with deionised water. Thus, the alkaline solutions mainly influence the dissolution kinetics of the anhydrous phases and not the kind of hydrates formed.

\section{Thermodynamic modelling}

Thermodynamic modelling was used to calculate the stable hydrate assemblages of ye'elimite/calcium sulfate mixtures and to compare those findings with the experimental results. In the calculations, the mixtures of ye'elimite and calcium sulfate were allowed to hydrate completely in deionised water at a water/solid ratio of 2 , as used in the calorimetric measurements. From a thermodynamic point of view there is no difference between gypsum and anhydrite addition, as they both are able to dissolve and react with the ye'elimite. The only difference is their dissolution 
kinetics. Thus, gypsum and anhydrite are referred to as calcium sulfate in this chapter.

The software originally predicted the formation of gibbsite instead of amorphous $\mathrm{Al}(\mathrm{OH})_{3}$, which is not in agreement with the experimental findings, as the conversion of amorphous to crystalline $\mathrm{Al}(\mathrm{OH})_{3}$ is kinetically hindered at room temperature. Also, some calcium aluminate hydrate $\mathrm{CAH}_{10}$ was predicted to form, but this is not confirmed by experimental data. It could be due to uncertainties of the thermodynamic data of $\mathrm{CAH}_{10}$ reported in [27]. Thus, the formation of both gibbsite and $\mathrm{Al}(\mathrm{OH})_{3}$ was suppressed in the software. At present, experiments are undertaken at the authors' institution in order to revise the thermodynamic data of $\mathrm{CAH}_{10}$. However, $\mathrm{CAH}_{10}$ may occur as hydration product in technical CSA cements, especially in those, which contain calcium aluminate CA as minor constituent [15].

Figure 9 shows the calculated phase assemblages of ye'elimite/calcium sulfate mixtures in a range between $100 \%$ ye'elimite and a 50/50 blend (in mass\%). The investigated molar mixtures are marked in the diagram as well as the boundaries between rapid hardening/high strength, expansive and self-stressing systems according to $[4,6]$.

The calculations reveal that monosulfate and amorphous aluminium hydroxide are the hydrate phases of pure ye'elimite. The occurrence of some ettringite (about $0.7 \mathrm{~cm}^{3} /$ $100 \mathrm{~g}$ of solid phase) was predicted as well, confirming the experimental results. However, the amount of ettringite found experimentally exceeds the calculated quantity. Thermodynamic calculations yield the stable phase assemblages and quantities, whereas the thermodynamic

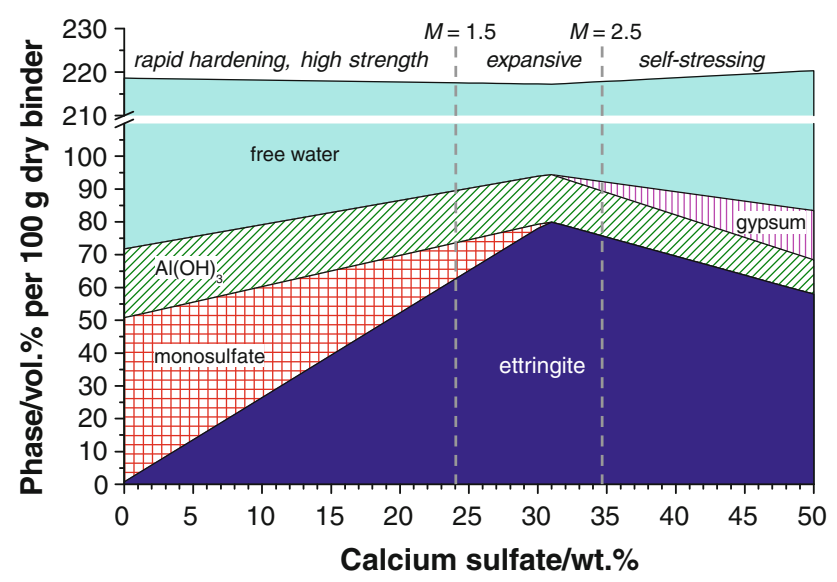

Fig. 9 Calculated phase diagram of the thermodynamic stable hydrate assemblages of the system ye'elimite-calcium sulfate-water at $20{ }^{\circ} \mathrm{C}$ and at a water/solid ratio of 2 . The mixtures investigated in this study are marked by arrows. The boundaries between rapid hardening/high strength, expansive and self-stressing according to [4, 6] are marked by dashed lines equilibrium might not be reached under experimental conditions, which could explain this discrepancy.

With increasing amount of calcium sulfate and decreasing amount of ye'elimite in the mixture, the quantity of monosulfate decreases and the amount of ettringite increases. The content of amorphous $\mathrm{Al}(\mathrm{OH})_{3}$ slightly decreases when calcium sulfate is added, as both reactions (see Eqs. 1, 2) form the same molar quantities of $\mathrm{Al}(\mathrm{OH})_{3}$. Therefore, the decrease is due to the dilution of the ye'elimite by the calcium sulfate addition, which leads to less aluminium in the mixture. The ettringite content reaches its maximum at a molar ratio of ye'elimite to calcium sulfate of 1:2. Beyond that molar ratio, monosulfate is no longer formed, but instead surplus calcium sulfate is present as gypsum, and the ettringite content decreases due to the dilution of the ye'elimite by the added calcium sulfate, leading to less aluminium in the mixture. The total volume of hydrates increases with increased calcium sulfate content until it reaches a maximum at a molar ratio of $1: 2$, then the volume of the hydrate phases decreases again. At this molar ratio, the total volume of the paste (free water plus hydrates) reaches a minimum, and the amount of chemically bound water a maximum. According to the formula given in $[4,6]$, ye'elimite-gypsum blends to the molar ratio of $1: 1.5$ and beyond are classified as expansive and self-stressing, confirming the fact that ettringite in the phase assemblage is responsible for the expansive processes.

\section{General discussion}

The heat flow of hydrating ye'elimite paste is characterised by an initial peak (first minutes), a long dormant period exhibiting a very low heat flow (until $10 \mathrm{~h}$ ) and a main peak with a maximum heat flow after $15 \mathrm{~h}$ of hydration, covering the main hydrations reactions. The long dormant period could be explained by a surface coverage of the clinker grains by early hydration products. Main hydration products are monosulfate and amorphous aluminium hydroxide besides ettringite.

The addition of gypsum accelerates the hydration of ye'elimite. At molar ratios gypsum to ye'elimite of 2 and higher, ettringite and $\mathrm{Al}(\mathrm{OH})_{3}$ are the only hydration products. At lower molar ratios, monosulfate starts to form instead of ettringite, when the gypsum is depleted. This is indicated in the calorimetric curve by a shoulder or an additional peak beyond the main hydration peak. Thus, a reactive calcium sulfate addition like gypsum is very suitable to control hydration and setting of ye'elimite pastes.

In contrast to gypsum, the less reactive anhydrite leads to more complicated early hydration kinetics. However, the phases formed are the same as with gypsum, but the 
kinetics of ettringite formation seems to be delayed. This could be due to the hindered dissolution of anhydrite causing a lack of calcium and sulfate ions in the pore solution. This probably slows down the dissolution of the ye'elimite, which could be blocked by early hydration products like amorphous $\mathrm{Al}(\mathrm{OH})_{3}$, which retard further hydration. The hydration can restart, when again a part of the anhydrite dissolves, and calcium and sulfate ions become available in the pore solution.

Besides calcium sulfates, solutions of potassium hydroxide are able to accelerate the hydration, by speeding up the dissolution kinetics of ye'elimite. They do not have a significant impact on the phase assemblage. Other alkaline solutions like sodium hydroxide would probably generate the same effect.

The thermodynamic stable phase assemblage of completely hydrated mixtures of ye'elimite and gypsum as calculated using a geochemical model (GEMS-PSI) is in a good agreement with the experimental data.

Concerning expansive processes, the formation of ettringite and its kinetics seems to be the key parameter. It can be controlled by the ratio of ye'elimite to calcium sulfate, as stated in the formula developed by $[4,6]$, see Eq. 3. In systems with low calcium sulfate additions, the ettringite formation is terminated shortly after setting. Thus, expansive ettringite reactions cannot occur. On the contrary, the expansive behaviour of systems with ettringite/gypsum molar ratios of about $1: 2$ and beyond is related to the ongoing formation of ettringite in systems after setting. Those systems exhibit a rigid structure, in which further ettringite formation may cause expansion according to the mechanisms described in [20].

\section{Conclusions}

It is shown by experimental data and thermodynamic modelling that the amount and the reactivity of calcium sulfate plays a key role in controlling the hydration of ye'elimite, the main phase of CSA cements. The quantity of calcium sulfate added to the clinker influences the ratio of the main hydrate phases ettringite and monosulfate. With increasing amounts of calcium sulfate, more ettringite is forming. This may lead to an expansive behaviour of the mixture, when high amounts of ettringite are forming within the hardened matrix. By the use of a reactive calcium sulfate like gypsum, setting behaviour and early strength properties can be controlled, whereas a low reactive calcium sulfate like some anhydrites cause a lack of calcium and sulfate ions in the pore solution, leading to a delay in ettringite formation and strength development.
Acknowledgements The authors express their thanks to Empa's lab team for their assistance in the experimental work. Dr. Barbara Lothenbach and Dr. Laure Pelletier are acknowledged for the fruitful discussions.

\section{References}

1. Gartner E. Industrially interesting approaches to "low- $\mathrm{CO}_{2}$ " cements. Cem Concr Res. 2004;34:1489-98.

2. Su M, Kurdowski W, Sorrentino F. Development in non-Portland cements. In: Ninth international congress on the chemistry of cements, New Delhi, India, Nov. 23-28, 1992, vol. I, p. 317-54.

3. Wang Y, Su M. The third cement series in China. World Cem. 1994;25(8):6-10.

4. Wang YM, Su MZ, Zhang L. Sulphoaluminate cement. China: Peking University Press; 1999, ISBN 7-5639-0819-6.

5. Zhang L, Su M, Wang Y. Development of the use of sulfo- and ferroaluminate cements in China. Adv Cem Res. 1999;11:15-21.

6. Zhang L. Microstructure and performance of calcium sulfoaluminate cements. $\mathrm{PhD}$ thesis, University of Aberdeen; 2000.

7. Glasser FP, Zhang L. High-performance cement matrices based on calcium sulfoaluminate-belite compositions. Cem Concr Res. 2001;21:1881-6.

8. Majling J, Znášik R, Gabrišová A, Svetík Š. The influence of anhydrite reactivity upon hydration of calcium sulphoaluminate cement clinker. Thermochim Acta. 1985;92:349-52.

9. Kaprálik I, Hanic F. Phase relation in the subsystem $\mathrm{C}_{4} \mathrm{~A}_{3} \overline{\mathrm{S}}$ $\mathrm{C} \overline{\mathrm{S}} \mathrm{H}_{2}-\mathrm{CH}-\mathrm{H}_{2} \mathrm{O}$ of the system $\mathrm{CaO}-\mathrm{Al}_{2} \mathrm{O}_{3}-\mathrm{C} \overline{\mathrm{S}}-\mathrm{H}_{2} \mathrm{O}$ referred to hydration of calcium sulphoaluminate cement. Cem Concr Res. 1989;19:89-102.

10. Hanic F, Kaprálik I, Gabrisová A. 1989 Mechanism of hydration reactions in the system $\mathrm{C}_{4} \mathrm{~A}_{3} \overline{\mathrm{S}}-\mathrm{C} \overline{\mathrm{S}}-\mathrm{CaO}-\mathrm{H}_{2} \mathrm{O}$ referred to hydration of sulphoaluminate cements. Cem Concr Res. 1989;19:67182.

11. Sahu S, Havlica J, Tomková V, Majling J. Hydration behaviour of sulphoaluminate belite cement in the presence of various calcium sulphates. Thermochim Acta. 1991;175:45-52.

12. Palou MT, Majling J. Hydration in the system $\mathrm{C}_{4} \mathrm{~A}_{3} \overline{\mathrm{S}}-\mathrm{C} \overline{\mathrm{S}} \mathrm{H}_{2}-\mathrm{CH}$. J Therm Anal. 1996;46:557-63.

13. Péra J, Ambroise J, Holard E, Beauvent G. Influence of the type of calcium sulfate on the properties of calcium sulfoaluminate cement. In: Eleventh international congress on the chemistry of cements, Durban, South Africa, May 11-16, 2003, vol. 3, p. $1129-35$.

14. Alaoui A, Nguyen VH, Divet L, Feraille A, Le Roy R. Experimental studies of hydration mechanisms of sulfoaluminate clinker. In: Twelve international congress on the chemistry of cement, Montreal, Canada, July 8-13, 2007, paper W3-11.6, 12.

15. Winnefeld F, Barlag S. Influence of calcium sulfate and calcium hydroxide on the hydration of calcium sulfoaluminate clinker. ZKG Int. (in press).

16. Winnefeld F, Lothenbach B. Hydration of calcium sulfoaluminate cements-experimental findings and thermodynamic modelling. Cem Concr Res. (in press). doi:10.1016/j.cemconres.2009.08.014.

17. Wang L, Glasser FP. Hydration of calcium sulphoaluminate cements. Adv Cem Res. 1996;8:127-34.

18. Zhang L, Glasser FP. Hydration of calcium sulfoaluminate cement at less than 24 h. Adv Cem Res. 2002;14:141-55.

19. Zhang L, Glasser FP. Investigation of the microstructure and carbonation of CSA-based concretes removed from service. Cem Concr Res. 2005;35:252-60.

20. Odler I. Special inorganic cements. 3rd ed. London: E \& FN Spon; 2000. 
21. Lura P, Winnefeld F, Klemm S. Simultaneous measurements of heat of hydration and chemical shrinkage on hardening cement pastes. J Therm Anal Calorim. 2009. doi:10.1007/s10973009-0586-2.

22. Franke B. Bestimmung von Calciumoxid und Calciumhydroxid neben wasserfreiem und wasserhaltigem Calciumsilicat. $\mathrm{Z}$ anorg allg Chem. 1941;247:180-4.

23. Wadsö L. Applications of an eight-channel isothermal conduction calorimeter for cement hydration studies. Cem Int. 2005;5:94-101.

24. Available at http://gems.web.psi.ch, version 2.2.4 rc7. Accessed July 25, 2008.

25. Available at www.empa.ch/cemdata, version cemdata07.2. Accessed August 26, 2008.

26. Lothenbach $B$, Winnefeld $F$. Thermodynamic modelling of the hydration of Portland cement. Cem Concr Res. 2006;36:209-26.
27. Matschei T, Lothenbach B, Glasser FP. Thermodynamic properties of Portland cement hydrates in the system $\mathrm{CaO}-\mathrm{Al}_{2} \mathrm{O}_{3}-$ $\mathrm{SiO}_{2}-\mathrm{CaSO}_{4}-\mathrm{CaCO}_{3}-\mathrm{H}_{2} \mathrm{O}$. Cem Concr Res. 2007;37:1379-410.

28. Doval M, Palou M, Kovár V. Heat evolution and mechanism of hydration in $\mathrm{CaO}-\mathrm{Al}_{2} \mathrm{O}_{3}-\mathrm{SO}_{3}$ system. Ceram Silik. 2005;49: 104-8.

29. Guan B, Lou W, Ye Q, Fu H, Wu Z. Calorimetric study of calcium aluminate cement blended with flue gas desulfurization gypsum. J Therm Anal Calorim. 2009. doi:10.1007/s10973009-0107-3.

30. Gastaldi D, Boccaleri E, Canonico F, Bianchi M. The use of Raman spectroscopy as a versatile characterization tool for calcium sulphoaluminate cements: a compositional study. J Mater Sci. 2007;42:8426-32. 